\title{
Punishment Induces Risky Decision-Making in Methadone-Maintained Opiate Users but not in Heroin Users or Healthy Volunteers
}

\author{
Karen D Ersche ${ }^{1,2}$, Jonathan P Roiser ${ }^{1,2}$, Luke Clark ${ }^{2,3}$, Mervyn London ${ }^{4}$, Trevor W Robbins ${ }^{2,3}$ \\ and Barbara J Sahakian*,1,2 \\ 'Department of Psychiatry, School of Clinical Medicine, Addenbrooke's Hospital, University of Cambridge, Cambridge, UK; ${ }^{2}$ MRC Centre \\ for Behavioural and Clinical Neuroscience, University of Cambridge, Cambridge, UK; ${ }^{3}$ Department of Experimental Psychology, \\ University of Cambridge, Cambridge, UK; ${ }^{4}$ Cambridge Drug \& Alcohol Service, Brookfields Hospital, Cambridge, UK
}

\begin{abstract}
Reinforcing properties of psychoactive substances are considered to be critically involved in the development and maintenance of substance dependence. While accumulating evidence suggests that the sensitivity to reinforcement values may generally be altered in chronic substance users, relatively little is known about the influence reinforcing feedback exerts on ongoing decision-making in these individuals. Decision-making was investigated using the Cambridge Risk Task, in which there is a conflict between an unlikely large reward option and a likely small reward option. Responses on a given trial were analyzed with respect to the outcome on the previous trial, providing a measure of the impact of prior feedback in modulating behavior. Five different groups were compared: (i) chronic amphetamine users, (ii) chronic opiate users in methadone maintenance treatment (MMT), (iii) chronic users of illicit heroin, (iv) ex-drug users who had been long-term amphetamine/opiate users but were abstinent from all drugs of abuse for at least I year and ( $\mathrm{v}$ ) matched controls without a history of illicit substance use. Contrary to our predictions, choice preference was modified in response to feedback only in opiate users enrolled in MMT. Following a loss, the MMT opiate group chose the likely small reward option significantly less frequently than controls and heroin users. Our results suggest that different opiates are associated with distinctive behavioral responses to feedback. These findings are discussed with respect to the different mechanisms of action of heroin and methadone.
\end{abstract}

Neuropsychopharmacology (2005) 30, 2I I5-2 I24. doi:I0. I038/sj.npp. I 3008I2; published online 6 July 2005

Keywords: methadone; heroin; risk-taking; decision-making; substance abuse; negative feedback

\section{INTRODUCTION}

The intake of addictive substances is thought to be motivated by the expected benefits associated with the substance, either in terms of pleasure (Robinson and Berridge, 1993; Wise, 1988) or as a relief from negative affect (Baker et al, 2004). Consequently, the reinforcing properties of drugs play an important part in both the development and the maintenance of substance dependence (Higgins et al, 2004; Koob and LeMoal, 1997). Different lines of investigation have suggested that sensitivity to reinforcement values may generally be altered in chronic substance users. For example, substance users frequently

\footnotetext{
*Correspondence: Professor BJ Sahakian, Department of Psychiatry, School of Clinical Medicine, University of Cambridge, Addenbrooke's Hospital, Box 189, Cambridge, Cambridgeshire CB2 2QQ, UK. Tel: + 44 I223 331209, Fax: + 441223 336968, E-mail: ke220@cam.ac.uk Received 20 January 2005; revised 19 April 2005; accepted 22 May 2005

Online publication: I June 2005 at http://www.acnp.org/citations/ Npp060 0505005 I/default.pdf
}

make decisions with a view to immediate gratification (Allen et al, 1998; Bickel and Marsch, 2001; Madden et al, 1999; Kirby et al, 1999; Petry, 2003), and may be less sensitive to negative future outcome ('myopia for the future') (Bechara et al, 1994; Bechara and Damasio, 2002). It has been hypothesized that substance users are less able to use negative feedback to guide and adjust ongoing behavior (Bechara et al, 2002). In the present study, we explored the impact of current and previous drug use on decision-making. In particular, we wished to determine how task feedback modified ongoing decision-making. We used the Cambridge Risk Task, in which participants must choose between an unlikely large reward option and a likely small reward option. Feedback was provided by the way of gain or loss of points following each trial. In contrast to pure guessing games, information about reinforcement values and outcome probability was provided, so that participants could make informed choices. We aimed not only to assess the impact of chronic drug use per se, but also to distinguish between the effects of amphetamines and opiates, in the light of conjecture that different motives may 
underlie the abuse of these two substances. It has been suggested that stimulant users maintain drug taking to experience exhilaration and increase self-esteem, whereas opiate users seek relief from tension and detachment from worry (Spotts and Shonts, 1980; Kreek et al, 2002). These differences may arise from the distinct pharmacological actions and pharmacokinetic properties of these two agents and may result in different approaches to dealing with feedback. We further aimed to explore whether amphetamines or the type of opiate used, methadone or heroin, impacts differentially on the way feedback modulates behavior. Although methadone is widely used as a substitute for heroin to treat opiate-dependent individuals, the pharmacodynamic effects of these opiates are quite distinct: methadone is a long-acting, full agonist of the muopioid receptor, which prevents opiate withdrawal for $24 \mathrm{~h}$, alleviates craving and stabilizes the hormonal disruptions caused by short-acting mu-opioid receptor agonists such as heroin (diacetylmorphine) (see Kreek, 2000, for review). Biochemical research suggests that methadone, in comparison to morphine, interacts differentially with respect to both the mu-opioid and delta-opioid receptor, resulting in distinct cellular processes, which may explain the reduced development of tolerance and altered addictive potential of methadone relative to heroin (Blake et al, 1997; Liu et al, 1999).

We hypothesized that drug-naïve participants would respond to a loss of points by adopting a more conservative tendency on the subsequent trial, and that this conservative response to feedback would be attenuated in drug use groups, and possibly dependent upon the pharmacological properties of the substance of abuse. Former drug users (exdrug users), who had been long-term users of amphetamines and opiates but were abstinent from all drugs of abuse for at least a year at the time of testing, were introduced to assess the reversibility of any effect with prolonged abstinence.

\section{METHODS}

\section{Participants}

The study was approved by the Local Research Ethics Committees (LREC) in Cambridge (00/405), Huntingdon (H01/635), Peterborough-Fenland (P01/145), and West Suffolk (03/021). A total of 116 participants were recruited for the study, all of whom provided written informed consent prior to participation. Current drug users were recruited through referrals from drug workers in the region and upon recommendations of participants. Ex-drug users were recruited via Narcotics Anonymous and controls by advertisements in the local area.

There were five groups: amphetamine users, opiate users maintained on methadone, opiate users taking only street heroin, ex-drug users and healthy volunteers without a history of illicit substance use. Current substance users all met the DSM-IV (American Psychiatric Association, 1994) criteria for substance dependence for either amphetamines or opiates for the past 3 years. Dependence on other illicit drugs or alcohol led to exclusion from the study, though nicotine dependence was tolerated. Current drug users also reported occasionally taking other illegal substances besides their substance of dependence, which are displayed in Table 1. Criteria for exclusion, which applied to all groups, were: a regular consumption of alcohol exceeding $21 \mathrm{U} /$ week for men and $14 \mathrm{U} /$ week for woman, a comorbid psychiatric illness, history of head injury, history of an overdose, which required resuscitation and overnight hospitalization. Prior to testing, urine samples were analyzed for the following drugs: morphine, methadone, amphetamine, cocaine, and benzodiazepines using the SureStep Drug Screen Test (Euromed Limited, London, UK). In all, 27 out of 39 opiate users were on a methadone prescription (mean \pm SD dose: $45 \pm 17.8 \mathrm{mg}$, dose range: $20-80 \mathrm{mg}$ ) (methadone maintenance treatment (MMT) group). Two also received benzodiazepines on prescription, one was on antidepressant medication (Dothiepin) and another was taking Rabeprazole Sodium for the treatment of heartburn. In all, 12 opiate users were using only street heroin. While all street heroin users were current tobacco smokers (mean \pm SD $18 \pm 12.2$ cigarettes per day), $96 \%$ opiate users in MMT were currently smoking tobacco (mean \pm SD $20 \pm 11.3$ cigarettes per day). All 39 opiate users tested positive for opiates. In all, 16 MMT opiate users were also positive for morphine and four heroin users for methadone. In all, 20 urine samples also tested positive for cocaine (10 of methadone users and 10 of heroin users) and 18 for benzodiazepines (12 of methadone users and six of heroin users). Seven out of the 24 amphetamine users received $d$-amphetamine on prescription from a Consultant Psychiatrist (mean \pm SD dose: $36 \pm 21.9 \mathrm{mg}$, dose range: $15-70 \mathrm{mg}$ ) but also used street amphetamine. One participant who received $d$-amphetamine was also prescribed benzodiazepines. Amphetaminedependent individuals without a prescription consumed street amphetamine daily. A total of $88 \%$ of amphetamine users were tobacco smokers (mean \pm SD $12 \pm 8.1$ cigarettes per day). One street amphetamine user was HIV positive. Out of 24 amphetamine users 22 tested positive for amphetamines. The urine screen of one amphetamine user was negative for amphetamine, but since he had consumed a large quantity of non-alcoholic liquids and the time window for detection of amphetamine in the urine is only 24-48 h (UK Department of Health, 1999), his data were included in the study. The other urine screen negative for amphetamine was positive for cocaine. Two other amphetamine users also tested positive for cocaine, two for benzodiazepines and six for opiates. All 26 ex-drug users had all been dependent on either amphetamines or opiates for at least 3 years and have been abstinent from all drugs of abuse (except nicotine) for at least 1 year (mean \pm SD years of abstinence $8.2 \pm 6.3$ ). Eight ex-drug users had been exstimulant (amphetamine and cocaine) users, five ex-opiate users and 13 had been dependent on both stimulants and opiates. Of ex-drug users $62 \%$ were current tobacco smokers (mean \pm SD $10 \pm 10.4$ cigarettes per day). All urine samples tested negative for all substances. One ex-drug user was on antidepressant medication (Cipramil) at the time of testing. All control participants had neither a drug-taking history nor received currently psychotropic medication. In all, 11 controls had smoked tobacco in the past and six were smoking tobacco currently (mean \pm SD $3 \pm 6.4$ cigarettes per day). Of these 12 participants had tried cannabis but never developed regular use. One participant was diabetic but was well controlled on insulin. Urine samples of all control 
Table I Percent of Illicit Drug and Alcohol Use per Group

\begin{tabular}{|c|c|c|c|c|c|}
\hline & & Amphetamine & Methadone & Heroin & Ex-drug \\
\hline \multirow[t]{3}{*}{ Amphetamine } & Never/rarely & 0 & 19 & 8 & 12 \\
\hline & Past & 0 & 78 & 92 & 88 \\
\hline & Present & 100 & 3 & 0 & 0 \\
\hline \multirow[t]{2}{*}{ Cocaine } & Never/rarely & 17 & 11 & 17 & 8 \\
\hline & Past & 46 & 56 & 42 & 92 \\
\hline \multirow[t]{3}{*}{ Ecstasy } & Never/rarely & 42 & 48 & 42 & 54 \\
\hline & Past & 54 & 52 & 58 & 46 \\
\hline & Present & 4 & 0 & 0 & 0 \\
\hline \multirow[t]{2}{*}{ Opiates } & Never/rarely & 46 & 0 & 0 & 12 \\
\hline & Past & 54 & 0 & 0 & 88 \\
\hline \multirow[t]{3}{*}{ Hallucinogenic } & Never/rarely & 38 & 37 & 17 & 23 \\
\hline & Past & 54 & 63 & 75 & 77 \\
\hline & Present & 8 & 0 & 8 & 0 \\
\hline \multirow[t]{3}{*}{ Cannabis } & Never/rarely & 21 & 4 & 0 & 12 \\
\hline & Past & 29 & 52 & 50 & 88 \\
\hline & Present & 50 & 44 & 50 & 0 \\
\hline \multirow[t]{3}{*}{ Alcohol } & Never/rarely & 42 & 37 & 33 & 19 \\
\hline & Past & 42 & 52 & 67 & 81 \\
\hline & Present & 16 & II & 0 & 0 \\
\hline
\end{tabular}

Table 2 Means and SD in Parentheses of Group Characteristics of Amphetamine, Opiate Users in MMT, Street Heroin Users, Ex-Drug Users and Control Participants Without a Drug-Taking History

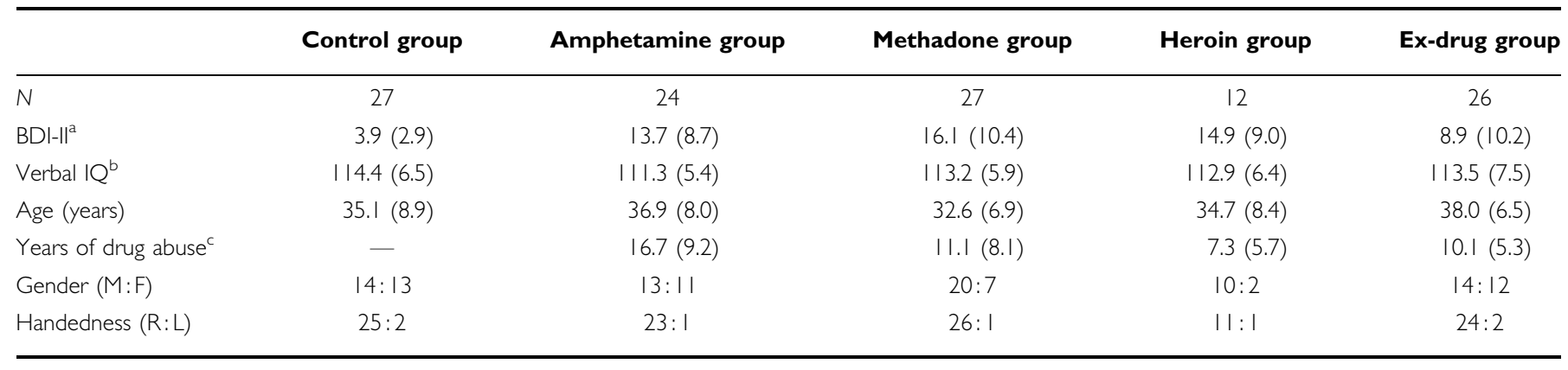

aeck Depression Inventory-II score (Beck et al, 1996)

berbal IQ was estimated using the National Adult Reading Test (NART) (Nelson, 1982).

'Years of drug abuse were assessed from the time that the drug of choice was regularly used (defined as at least four times a week).

participants tested negative for all substances. Further group characteristics including age, gender, handedness, verbal intelligence, Beck Depression Inventory II scores, and years of drug abuse are displayed in Table 2.

\section{Task}

Risky decision-making was investigated using the Cambridge Risk Task (Rogers et al, 1999), which requires participants to choose between two mutually exclusive options with different probabilities of reward and punishment. On each trial, an array of six boxes was presented on the screen, with a ratio of red and blue boxes $(3: 3,4: 2,5: 1$ boxes) that varied from trial to trial. Participants were told that the computer had hidden a yellow token, at random, behind one of the six boxes and they needed to decide whether the token was hidden behind a red or blue box. Their decision on each trial was shaped by a fixed bet associated with each alternative regarding the magnitude of potential gain or loss $(90: 10,80: 20 ; 70: 30 ; 60: 40 ; 50: 50$ 


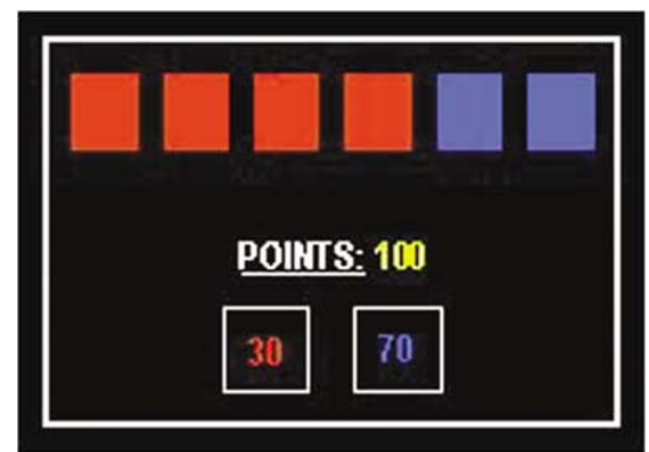

Figure I Screen shot of the Cambridge Risk Task. Participants were asked to decide whether a yellow token was hidden behind a red or a blue box. Each decision risked a loss or a gain of a certain number of points associated with the color on that trial. The most likely option was always associated with the small reward value.

points). In the example in Figure 1, two blue boxes and four red boxes are displayed. The blue boxes are less likely to yield the token but are associated with a 70-point gamble. The red boxes are more likely but involve only a 30-point gamble. Since each trial is independent from its predecessor, learning effects are obviated. On $80 \%$ of trials the probabilities are unequal and the large reward is always associated with the least likely outcome. Participants then have to decide whether to play safe and choose the likely option, which is associated with a small reward, or whether to take a risk and select the unlikely option, which is associated with a large reward. However, playing safe does not imply participants are guaranteed to receive reward, since on $1 / 4$ of trials the likely small reward option will result in loss. Participants started with 100 points available and indicated their choice on each trial by touching a red or blue square at the bottom of the screen. We sought to investigate how often participants made optimal choices (ie selecting the likely small reward option), and whether these choices were modified by feedback (a win or a loss) on the previous trial. When analyzing the effect of feedback on decision-making, we collapsed across risky and safe choices on the previous trial in order to simplify the analysis.

\section{Statistical Analysis}

Data were analyzed using the Statistical Package for Social Sciences (SPSS) version 11 (SPSS Inc.). Latency data, years of substance abuse, and BDI-II depression scores were square root transformed and proportion data were arcsine transformed to reduce skew (Howell, 1997). After transformation all data were normally distributed, as assessed by the Kolmogorov-Smirnov test. One-way analyses of variance (ANOVA) were used to explore group differences in age, verbal IQ, and depression as measured by the BDI-II. Group differences regarding handedness, gender, and the results of the urine screens were analyzed via $\chi^{2}$ or Fisher's exact procedures. Pearson's correlations were two-tailed and significance level of 0.05 was assumed. Risky decisionmaking was analyzed by extracting the $80 \%$ of trials with uneven probabilities, on which the least likely option was always associated with the large reward. Since the choices of the likely small reward and risky large reward option were mutually exclusive, we included only the proportion of choices of the likely option in analyses. Our main measure was the proportion of trials on which the participant chose the most likely outcome, which was always associated with a small reward value. We analyzed proportionate choice of the likely outcome across all trials (ie reflecting the overall optimal choices), and separately on trials following a win and on trials following a loss. Group differences on the overall proportion of likely choices were explored via univariate ANOVA. We then analyzed the proportion of likely option choices on trials following a win and following a loss using repeated-measures ANOVA. In order to compare group differences regarding the modulation of feedback on the choice of the likely option, we computed an individual difference score (ie likely choices following a win were subtracted from likely choices following a loss), reflecting whether the likely option was chosen preferably following positive or negative feedback. Group comparisons on the difference score were carried out via univariate ANOVA. Risky decision-making following negative feedback was explored using an analysis of covariance (ANCOVA) on the proportion of likely choices following negative feedback with proportion of choices following positive feedback as a covariate. If not specified otherwise, post hoc tests, thresholded at level $p<0.05$, were conducted using the Tukey test if variances were equivalent between groups or the Tamhane procedure if variances differed between the groups. The latency of the proportion of likely choices was analyzed in the same way as the proportional choices described above.

\section{RESULTS}

\section{Group Characteristics}

Demographic characteristics and questionnaire scores are displayed in Table 2. The groups did not differ in regard to age, gender, handedness, or verbal IQ. Moreover, the drug user groups did not differ in terms of years of drug abuse. Regarding the urine screens, the three current drug user groups differed in respect to urine samples tested positive for cocaine (Fisher's exact test, $p=0.002$ ) and benzodiazepines (Fisher's exact test, $p=0.004$ ). Comparisons between the two opiate user groups showed a significant difference regarding samples that tested positive for cocaine (Fisher's exact test, $p=0.041$ ) such as more heroin users tested positive for cocaine than methadone users. Heroin and methadone users did not differ regarding urine samples tested positive for benzodiazepines. For the daily number of cigarettes smoked, the groups differed significantly $\left(\mathrm{F}_{4,108}=12.32, p<0.001\right)$. All current drug users smoked more cigarettes than controls $(p<0.001$ for methadone and heroin, $p=0.005$ for amphetamine). Methadone users smoked significantly more cigarettes than ex-drug users $(p=0.002)$ and at trend level also more cigarettes than amphetamine users $(p=0.054)$. However, the number of daily cigarettes did not correlate with any outcome measure. All of the current drug users scored higher on the BDI-II than controls $\left(\mathrm{F}_{4,111}=11.48 ; p<0.001\right.$ for all $)$. Furthermore, both amphetamine and methadone users scored significantly higher on the BDI-II relative to ex-drug users 
( $p=0.022$ amphetamines; $p=0.006$ methadone). Since BDIII total score correlated with the overall proportion of likely choices $(r=-0.19, p=0.040)$ it was included in the analyses as a covariate.

\section{Decision-Making Performance}

Overall, all five groups had a conservative gambling strategy and preferred the likely small reward option (likely or optimal choice) to the unlikely large reward option (risky choice). Controls chose the likely option on $83 \%$ of trials, amphetamine users on $75 \%$, methadone users on $78 \%$, heroin users in $87 \%$, and ex-drug users on $75 \%$ of trials (see Table 3). There was no effect of group on the overall preferred choice $\left(\mathrm{F}_{4,110}=1.69, p=0.157\right)$. The effect of feedback on proportionate likely choice was analyzed using repeated-measures ANOVA, with feedback (two levelspositive/negative) as the within-subject factor and group (five levels - controls, ex-drug, amphetamine, heroin, methadone) as the between-subject factor. A highly significant feedback $\times$ group interaction was identified for the choice of the most likely option $\left(\mathrm{F}_{4,110}=4.04, p=0.004\right)$. To carry out a post hoc analysis we calculated an individual difference scores of the proportion of likely options chosen with respect to feedback (ie negative-positive feedback). As can be seen from Figure 2, negative feedback induced greater risk-taking than positive feedback in the methadone group but not in any of the other groups. This differential effect of task feedback on decision-making was significantly greater in the methadone group than in controls $(p=0.003)$ and heroin users $(p=0.010)$. The difference between the methadone users and amphetamine users $(p=0.059)$ and ex-drug users $(p=0.072)$ was evident at trend levels. Since we were specifically interested in investigating the effect of negative feedback on decision-making, we analyzed proportionate choice of the likely outcome following negative feedback between the groups while statistically controlling for proportionate choice of the likely option following positive feedback in a covariate analysis. This ANCOVA revealed a highly significant main effect of group $\left(\mathrm{F}_{4,110}=4.58, p=0.002\right)$. The covariate was also significant $\left(\mathrm{F}_{4,110}=187.17, p<0.001\right)$ but the group $\times$ covariate interaction was not significant, and was therefore removed from the analysis. Post hoc analysis of the main effect of group using Bonferroni-corrected pairwise comparisons indicated that methadone users chose the likely option significantly

Table 3 Means and SD of the Proportionate Choice of the Likely Option and Overall Latency

\begin{tabular}{|c|c|c|c|c|c|}
\hline Task measures & Controls & Amphetamines & Methadone & Heroin & Ex-drug \\
\hline Overall proportion of choices for the likely option & $0.83(0.15)$ & $0.75(0.18)$ & $0.78(0.17)$ & $0.87(0.10)$ & $0.75(0.20)$ \\
\hline Trials following a loss: proportion of the likely options chosen & $0.84(0.16)$ & $0.75(0.21)$ & $0.74(0.19)$ & $0.88(0.15)$ & $0.75(0.22)$ \\
\hline Trials following a win: proportion of the likely options chosen & $0.82(0.16)$ & $0.76(0.18)$ & $0.81(0.16)$ & $0.86(0.09)$ & $0.75(0.20)$ \\
\hline Overall latency $(s)$ & $3.15(1.20)$ & $2.37(0.91)$ & $2.72(1.41)$ & $2.25(0.69)$ & $1.99(0.62)$ \\
\hline Trials following a win: latency of likely option choices (s) & $3.17(1.21)$ & $2.47(0.97)$ & $2.80(1.49)$ & $2.21(0.79)$ & $2.06(0.68)$ \\
\hline
\end{tabular}

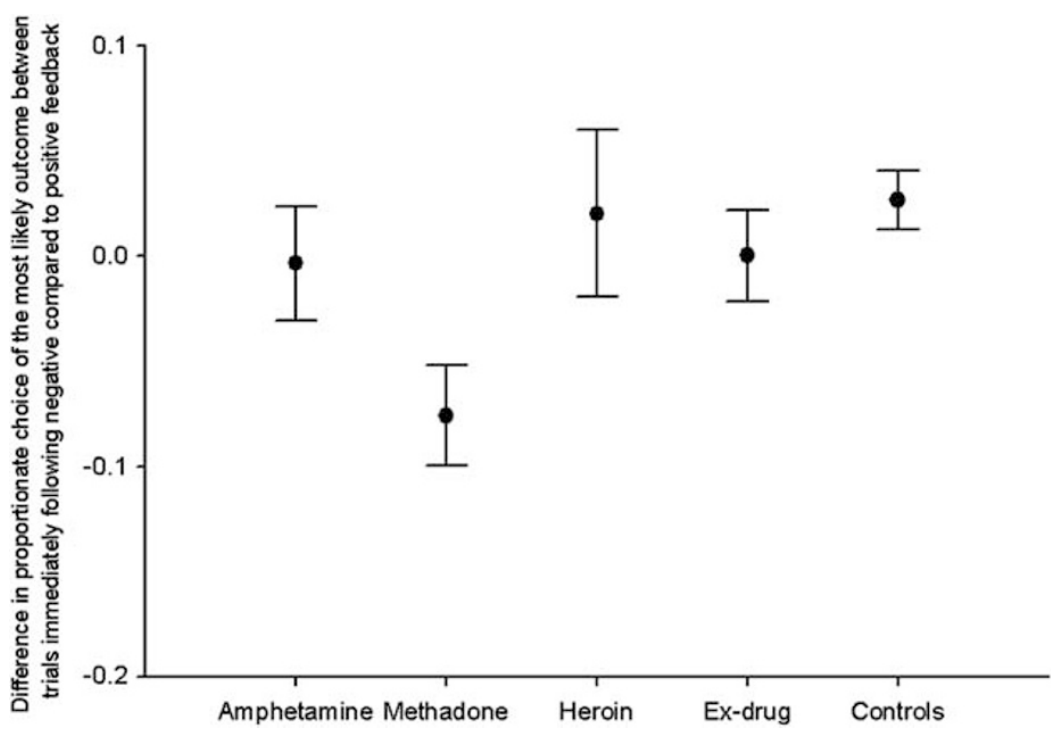

Figure 2 Mean difference $( \pm S E M)$ in proportionate choice for the most likely small reward option in respect to feedback (ie choices following a loss minus choices following a win). Negative feedback induced greater risk-taking than positive feedback in the methadone group but not in any of the other groups. This differential effect of task feedback on decision-making was significantly greater in methadone-maintained opiate users than in controls $(p=0.003)$ and street heroin users $(p=0.010)$. 
less frequently following a loss than controls $(p=0.003)$ and heroin users $(p=0.010)$. In other words, although the groups did not differ with respect to their overall choice of the likely small reward option, they did differ in terms of the effect that prior feedback had on their decision-making behavior. When we controlled for the variance in proportionate choice of the likely outcome following a win, it became apparent that methadone users exhibited a risktaking strategy following a loss, choosing the likely small reward option significantly less frequently compared to both controls and heroin users.

Overall, the ex-drug users responded significantly faster than all the other groups (main effect of group: $F_{4,110}=5.80$, $p<0.001$; post hoc: $p=0.001$ ) (see Table 3 ). The repeatedmeasures ANOVA on the latency for the likely option in respect to feedback identified a highly significant feedback $\times$ group interaction $\left(\mathrm{F}_{4,110}=5.34, p=0.001\right)$. To carry out post hoc analysis, we calculated individual difference scores of the latency to choose the likely options with respect to feedback (ie negative-positive feedback). The exdrug users were significantly faster in choosing the likely option following negative feedback compared to positive feedback relative to controls $(p=0.003)$ (data not displayed). However, when we statistically controlled for latency to choose the likely option following positive feedback in a covariate analysis, the main effect of group was not significant $\left(\mathrm{F}_{4,110}=0.24, p=0.918\right)$. In other words, ex-drug users were generally faster than the other groups and selected the likely option faster following negative feedback compared to positive feedback relative to controls. However, since the ANCOVA analysis, which controlled for the variance of the latency of likely choices following a win, was not significant, we cannot safely conclude that this effect was specifically related to negative feedback.

In view of the significant difference in responses to negative feedback between the two opiate user groups, we divided the opiate users enrolled in MMT on the basis of the urine analysis into those whose urine tested positive only for methadone (MMT-, $n=11$ ) and those whose urine tested positive for morphine in addition to methadone $(\mathrm{MMT}+, n=16)$. The difference scores on likely choices with respect to feedback were qualitatively very similar $($ mean \pm SD, MMT $+:-0.06 \pm 0.11$; MMT $-:-0.11 \pm 0.14)$ and the repeated measures analysis did not identify a significant group $\times$ feedback interaction $\left(\mathrm{F}_{1,25}<1\right)$. We did the same subdivision for the heroin group by separating those heroin users who tested positive for heroin $(\mathrm{H}-$, $n=8$ ) and those who tested positive also for methadone $(\mathrm{H}+, n=4)$. Again the difference scores on likely choices with respect to feedback were qualitatively very similar (mean $\pm \mathrm{SD}, \mathrm{H}+: 0.01 \pm 0.14 ; \mathrm{H}-: 0.05 \pm 0.16$ ), though the numbers in each group were too small to make a meaningful comparison.

With regard to the positive urine screens for cocaine $(C)$ and benzodiazepines (B) among the current drug user groups, we explored a possible influence on choice selection with respect to feedback using repeated-measures ANOVA as described above. Thus, we first divided current drug users into $\mathrm{C}+($ mean $\pm \mathrm{SD}:-0.04 \pm 0.14)$ and $\mathrm{C}-$ (mean \pm SD: $-0.03 \pm 0.13$ ), but identified no significant group $\times$ feedback interaction $\left(F_{1,61}<1\right)$. Similarly, the analysis of $B+($ mean $\pm S D:-0.04 \pm 0.09)$ and $B-($ mean $\pm S D$ : $-0.03 \pm 0.15)$ participants did not produce a significant group $\times$ feedback interaction $\left(\mathrm{F}_{1,61}<1\right)$.

In summary, although the groups did not differ in regard to their overall decisions (they all chose the likely small reward option more frequently than the risky option), they significantly differed with respect to the way in which feedback modulated their choices. Methadone users exhibited risky decision-making following a loss of points relative to a gain of points, a significantly different response to feedback compared to controls and heroin users. Analysis of proportionate choice of the likely option following a loss while controlling for choice selection following a win confirmed the different decision-making strategies between the groups. Methadone users chose the likely option significantly less frequently following a loss compared to both controls and heroin users.

\section{DISCUSSION}

This study investigated how reinforcing feedback modulates ongoing decision-making in chronic opiate users, chronic amphetamine users, former drug users and controls. Opiate users enrolled in MMT were significantly more likely to make risky decisions when they had been unsuccessful on the previous trial. Following a loss of points, they exhibited a risk-taking strategy, choosing the likely small reward option significantly less frequently than controls and heroin users. It is remarkable that the risky response selection following a loss in methadone users was not shown in opiate users who only used illicit heroin. This finding was in contrast to expectations, since heroin users lead risky lives both in terms of medical complications, due to the variable quality of street heroin and intravenous drug use, as well as in terms of legal problems involved in obtaining the drug (Farabee et al, 2001; Neiman et al, 2000). Users under MMT, on the other hand, have opted to be maintained and monitored in a less risky manner (Koester et al, 1999). Yet, it was the latter group who appeared to show this increased risk-taking behavior following a loss.

At first glance, the increased risk-taking behavior following a loss of points suggests a hypersensitivity to punishment in methadone-maintained opiate users. Declining the likely small reward option after having suffered a loss could reflect an enhanced desire to make up the lost points. Thus, it might also be argued that a loss of points triggered impulsive responses in methadone users, which over-rode reflective strategies for selecting the most appropriate response. However, response latencies were the fastest in ex-drug users relative to all the other groups but they did not show increased risk-taking behavior following a loss. Thus, fast responding at the expense of sufficient reflection cannot explain the risk-taking strategy following losing. It is noteworthy that $65 \%$ of our ex-drug users had been in MMT, but at the time of testing, the quality of decision-making was not significantly different from controls. This would suggest that individuals who opt to enrol in MMT are not risk-taking per se, but that the nature of the opioid received in treatment might have an influence on the feedback processing during decisionmaking. 
With respect to the specific characteristics of the Cambridge Risk Task, which requires a decision between options that differ in the magnitude and likelihood of reward, risk-taking behavior may not only have been encouraged by the prospect of a greater reward but also be due to an underestimation of the risk involved. On the Iowa Gambling Task, a decision-making task that requires a series of card selections concerning winning and losing monetary rewards, it has been reported that methadone users show a selective preference for risky options on conditions involving a low frequency of penalty (Mintzer and Stitzer, 2002). As in our task, overall decision-making was not significantly impaired in methadone users (ie the overall gambling net score did not differ significantly from controls), but disadvantageous choices emerged on conditions when the perception of penalty was less obvious. Thus, methadone users chose advantageously at high-penalty frequency but disadvantageously at low-penalty frequency. This gambling strategy stands in sharp contrast to the impaired decision-making on the Iowa Gambling Task seen in stimulant and alcohol users, who generally make risky decisions throughout (as reflected in a significantly higher gambling net score relative to controls) (Bechara et al, 2001; Bechara and Damasio, 2002). Moreover, as in our study, the gambling strategy exhibited by former opiate users who had been under MMT but were now abstinent was indistinguishable from controls (Mintzer et al, 2005). The authors suggested that opiate users currently enrolled in MMT have altered saliency and/or immediacy of penalties (Mintzer and Stitzer, 2002).

While reward processing in substance using populations has been intensively studied in recent years, the processing of punishment and risk perception, which could lead to disadvantageous choices, has received far less attention. Relatively, little is known about the underlying mechanisms of risk perception but one important candidate neurotransmitter is noradrenaline (NA), a key neurotransmitter for the 'fight-or-flight' decision in a state of increased arousal (Amaral and Sinnamon, 1977; Selye, 1952). Recently, Rogers et al (2004) found that volunteers given the beta-adrenoreceptor-blocking drug propranolol showed disadvantageous decision-making by choosing a large gamble when the chances of winning were low. As in our task, participants had to make a choice between two options, which were presented simultaneously but, in contrast to our task, the magnitude of the gamble and probabilities associated with each option were independent from each other. They found that when the probability of winning was low, volunteers on propranolol made disadvantageous decisions, as they selected the option that involved a large gamble significantly more frequently than volunteers on placebo. The authors suggested that betaadrenoreceptor blockade attenuates the processing of punishment signals under conditions of increased arousal. Participants on propranolol and on placebo, however, did not differ in their choices when the probability of winning was high. According to Rogers et al (2004), this is due to the fact that the system processing reward is modulated by serotonin (Rogers et al, 2003), and therefore had not been affected by propranolol.

In light of the pronounced reward-conflict in the Cambridge Risk task between an unlikely small reward option and a likely large reward option, the similarities in disadvantageous response selection of methadone users and volunteers on propranolol are interesting. Both groups made disadvantageous choices by rejecting the conservative option involving the risk of only a small loss. The similar response pattern suggests that our unexpected finding may be elucidated by considering the influence that methadone exerts on noradrenergic activity. Accumulating evidence suggests that methadone-maintained opiate users have lower concentrations of NA in blood plasma relative to healthy controls (Kienbaum et al, 2001; Stine et al, 2001, 2002). Furthermore, it has been shown that chronic muopioid receptor stimulation by methadone exerts similar cardiac effects as propranolol: methadone causes problems in the control of the cardiovascular sympathetic system and has an impact on efferent sympathetic nerve activity to muscle and heart (Kienbaum et al, 2001, 2002). On the basis of these findings, we hypothesize that altered response to punishment in opiate users taking methadone may be a result of NA-downregulation due to the chronic mu-opioid receptor stimulation by a methadone maintenance regimen. Reduced baseline NA levels may be a disadvantage during risk perception, in particular when the risk involved is less salient. Although all information regarding the magnitude of the reward/punishment and the probability of the outcome were clearly displayed in the Cambridge Risk task, it is possible that the loss of points on the previous trial did not increase arousal in methadone users sufficiently to promote the tendency of 'playing safe'. However, further studies comparing indices of NA levels in methadonemaintained opiate users and heroin users would help to clarify whether altered response to punishment in methadone users is caused by NA system alterations.

It is also possible that altered responses to penalty in methadone users are the result of a central dysregulation in the processing of punishment. The anterior cingulate cortex (ACC) is a key region implicated in conflict monitoring, pain affect, and in the assessment of emotional valence and motivational impact of possible outcomes (Bush et al, 2000; Carter et al, 1998; Gehring and Willoughby, 2002; Kerns et al, 2004; Rainville, 2002). It has been reported that methadone-maintained opiate users show an attenuated response to errors in this region (Forman et al, 2004), and that activity in the ACC during cognitive performance is related to the sympathetic modulation of heart rate (Critchley et al, 2003); an intriguing finding in light of the fact that cardiac effects induced by methadone are far more potent than those induced by morphine or codeine (Katchman et al, 2002; Krantz et al, 2003). Although abnormalities in ACC activation are not unusual in psychiatric disorders (see Devinsky et al, 1995; Yucel et al, 2003, both for review) and in substance users (see Garavan and Stout, 2005, for review), differences in ACC function between opiate users maintained on methadone and on morphine, have to our knowledge not been investigated. In light of the important impact abnormal responses to negative feedback may have on learning and social functioning, research into feedback processing using neuroimaging techniques in opiatedependent individuals is needed to better understand abnormal behavioral responses within this patient group.

Although the groups were well matched on variables such as age, verbal IQ, gender, and handedness, and the current 
user groups did not differ in terms of years of drug use, cigarette smoking, and BDI scores, we need to briefly address possible confounds of the results. First, urine samples provided by current drug users on the day of testing differed in regard to additional positive results for cocaine and benzodiazepines. Yet, there was no significant difference in choice selection following feedback between drug users with and without cocaine or benzodiazepines in their urine. The additional illicit heroin use of the 16 methadone users did not change the response bias towards risk-taking following a loss of points. The additional illicit methadone use of the four street heroin users, who reported taking methadone approximately a fortnight prior to testing due to a shortage in heroin supply and financial difficulties, did not change the results of the heroin group. It is noteworthy that a positive urine screen for methadone after this period of time is not unusual since methadone's nonpharmacologically active primary metabolite 2-ethylidene1.5-dimethyl-3.3-diphenylpyrrolidine (EDDP) is detectable in the urine up to 9 days after last methadone intake (UK Department of Health, 1999; Wolff, 2003). In heroin users, who have not been stabilized on methadone, the elimination time may be even longer (Wolff, 2003). The fact that choice selection with respect to feedback did not differ between the heroin users with and without methadone-positive urine, is consistent with the reported stopgap use of illicit methadone.

Second, we did not assess the time of the last drug intake but all current drug users were dependent on their drug of choice, which they reported taking at least once a day. It could, however, be argued that the abnormal choice selection might be a result of insufficient dosage of methadone in the MMT group, which would affect cognitive function (Lyvers and Yakimoff, 2003). However, it is unlikely that the altered response to feedback in this group is attributable to early withdrawal, since discontinuation of the chronic mu-opioid receptor stimulation would have resulted in excessively high NA levels, which typically produce the symptoms of opiate withdrawal (Maldonador, 1997; Nestler et al, 1999). Not only did we observe any symptoms of withdrawal in our current drug users, but also the pattern of choice selection of methadone users would rather suggest reduced levels of NA.

Third, regarding the high depression scores in the current drug user groups and the evidence in the literature of abnormal responses to negative feedback in depressed patients (Elliott et al, 1997; Murphy et al, 2003), it should be noted that the methadone users were not significantly more depressed than amphetamine users or heroin users, who both showed normal responses to negative feedback. The fact that our findings survived the correction of using the BDI-II depression scores as a covariate indicates that depression did not influence the abnormal response in our methadone group. In view of the large symptom overlap between depression and substance abuse, previous research has recommended higher BDI-II cutoff scores for substance-dependent populations (35 for substance users relative to 14 for non-substance using populations) to avoid an overdiagnosis of clinical depression (Buckley et al, 2001). In other words, the high BDI depression scores in our current drug users may not reflect clinical depression.
In summary, we investigated how task feedback modifies decision-making in current and former chronic users of amphetamine and opiates and nondrug-taking-matched controls. We found that, following a loss of points, only methadone-maintained opiate users exhibited risk-taking behavior, while controls and heroin users were more inclined to 'play safe' following negative feedback. To our knowledge, this is the first time that abnormal choice preferences in response to negative feedback have been found in opiate users enrolled in MMT but not in street heroin users. Since the two opiate groups were matched on other descriptive variables collected such as years of drug abuse, gender, depression score, handedness, age or verbal IQ, one possible way of explaining the behavioral differences focuses on the nature of the opiate being used. We hypothesize that this unexpected risky decision-making behavior in response to punishment may possibly be a result of reduced NA levels in methadone-maintained opiate users. However, further studies are needed to investigate such differences systematically between opiate users maintained on methadone and heroin users. Since feedback processing plays an important role, not only in decisionmaking, but also in learning and social functioning, further investigation of this impairment in methadone users is warranted; this may provide useful insight for enhancing therapeutic effectiveness for opiate addiction.

\section{ACKNOWLEDGEMENTS}

We would like to thank our volunteers without whom this study would not have been possible, particularly those who aided with recruitment, as well as the key workers Nick Schiller and Marion Martin and members of Narcotics Anonymous. We also thank Dr Robert Rogers for providing the Risk Task and Dr George Ploubidis for statistical advice. This work was funded by a Wellcome Trust Programme Grant (no. 019407) to Professors Trevor Robbins, Barry Everitt, Barbara Sahakian and, Dr Angela Roberts and carried out within the MRC Centre for Behavioural and Clinical Neuroscience. Karen Ersche was supported by the Fund for Addenbrooke's and Jonathan Roiser by the Medical Research Council. The authors declare that they have no conflict of interests.

\section{REFERENCES}

Allen TJ, Moeller FG, Rhoades HM, Cherek DR (1998). Impulsivity and history of drug dependence. Drug Alcohol Dependence 50: 137-145.

Amaral DG, Sinnamon HM (1977). The locus coeruleus: neurobiology of a central noradrenergic nucleus. Prog Neurobiol 9: 147-196.

American Psychiatric Association (1994). Diagnostic and Statistical Manual of Mental Disorders 4th edn American Psychiatric Association: Washington, DC.

Baker TB, Piper ME, McCarthy DE, Majeskie MR, Fiore MC (2004). Addiction motivation reformulated: an affective processing model of negative reinforcement. Psychol Rev 111: 33-51.

Bechara A, Damasio AR, Damasio H, Anderson SW (1994). Insensitivity to future consequences following damage to human prefrontal cortex. Cognition 50: 7-15. 
Bechara A, Damasio H (2002). Decision-making and addiction (part I): impaired activation of somatic states in substance dependent individuals when pondering decisions with negative future consequences. Neuropsychologia 40: $1675-1689$.

Bechara A, Dolan S, Denburg N, Hindes A, Anderson SW, Nathan PE (2001). Decision-making deficits, linked to a dysfunctional ventromedial prefrontal cortex, revealed in alcohol and stimulant abusers. Neuropsychologia 39: 376-389.

Bechara A, Dolan S, Hindes A (2002). Decision-making and addiction (part II): myopia for the future or hypersensitivity to reward? Neuropsychologia 40: 1690-1705.

Beck AT, Steer RA, Brown GK (1996). Manual for Beck Depression Inventory-II. Psychological Corporation: San Antonio, TX.

Bickel WK, Marsch LA (2001). Toward a behavioral economic understanding of drug dependence: delay discounting processes. Addiction 96: 73-86.

Blake AD, Bot G, Freeman JC, Reisine T (1997). Differential opioid agonist regulation of the mouse mu opioid receptor. J Biol Chem 272: 782-790.

Buckley TC, Parker JD, Heggie J (2001). A psychometric evaluation of the BDI-II in treatment-seeking substance abusers. J Substance Abuse Treatment 20: 197-204.

Bush G, Luu P, Posner MI (2000). Cognitive and emotional influences in anterior cingulate cortex. Trends Cognitive Sci 4: 215-222.

Carter CS, Braver TS, Barch DM, Botvinick MM, Noll D, Cohen JD (1998). Anterior cingulate cortex, error detection, and the online monitoring of performance. Science 280: 747-749.

Critchley HD, Mathias CJ, Josephs O, O’Doherty J, Zanini S, Dewar BK et al (2003). Human cingulate cortex and autonomic control: converging neuroimaging and clinical evidence. Brain 126: 2139-2152.

Devinsky O, Morrell MJ, Vogt BA (1995). Contributions of anterior cingulate cortex to behavior. Brain 118: 279-306.

Elliott R, Sahakian BJ, Herrod JJ, Robbins TW, Paykel ES (1997). Abnormal response to negative feedback in unipolar depression: evidence for a diagnosis specific impairment. J Neurol Neurosurg Psychiatr 63: 74-82.

Farabee D, Joshi V, Anglin MD (2001). Addiction careers and criminal specialization. Crime Delinquency 47: 196-220.

Forman SD, Dougherty GG, Casey BJ, Siegle GJ, Braver TS, Barch DM et al (2004). Opiate addicts lack error-dependent activation of rostral anterior cingulate. Biol Psychiatr 55: 531-537.

Garavan H, Stout JC (2005). Neurocognitive insights into substance abuse. Trends Cognitive Sci 9: 195-201.

Gehring WJ, Willoughby AR (2002). The medial frontal cortex and the rapid processing of monetary gains and losses. Science 295: 2279-2282.

Higgins ST, Heil SH, Lussier JP (2004). Clinical implications of reinforcement as a determinant of substance use disorders. Ann Rev Psychol 55: 431-461.

Howell DC (1997). Statistical Methods for Psychology. Duxbury Press: London.

Katchman AN, McGroary KA, Kilborn MJ, Kornick CA, Manfredi $\mathrm{PL}$, Woosley RL et al (2002). Influence of opioid agonists on cardiac human ether-a-go-go-related gene $\mathrm{K}+$ currents. J Pharmacol Exp Ther 303: 688-694.

Kerns JG, Cohen JD, MacDonald AW, Cho RY, Stenger VA, Carter CS (2004). Anterior cingulate conflict monitoring and adjustments in control. Science 303: 1023-1026.

Kienbaum P, Heuter T, Scherbaum N, Gastpar M, Peters J (2002). Chronic mu-opioid receptor stimulation alters cardiovascular regulation in humans: differential effects on muscle sympathetic and heart rate responses to arterial hypotension. J Cardiovasc Pharmacol 40: 363-369.

Kienbaum P, Heuter T, Michel MC, Scherbaum N, Gastpar M, Peters J (2001). Chronic $\backslash\{$ micro $\backslash\}$-opioid receptor stimulation in humans decreases muscle sympathetic nerve activity. Circulation 103: 850-855.

Kirby KN, Petry NM, Bickel WK (1999). Heroin addicts have higher discount rates for delayed rewards than non-drug-using controls. J Exp Psychol: Gen 128: 78-87.

Koester S, Anderson K, Hoffer L (1999). Active heroin injectors' perceptions and use of methadone maintenance treatment: cynical performance or self-prescribed risk reduction? Substance Use Misuse 34: 2135-2153.

Koob GF, LeMoal M (1997). Drug abuse: hedonic homeostatic dysregulation. Science 278: 52-58.

Krantz MJ, Martell BA, Arnsten JH, Gourevitch MN (2003). Medications that prolong the QT interval. JAMA 290: 1025.

Kreek MJ (2000). Methadone-related opioid agonist pharmacotherapy for heroin addiction-history, recent molecular and neurochemical research and future in mainstream medicine. New Medications Drug Abuse 909: 186-216.

Kreek MJ, LaForge KS, Butelman E (2002). Pharmacotherapy of addictions. Nature Rev Drug Discovery 1: 710-726.

Liu JG, Liao XP, Gong ZH, Qin BY (1999). The difference between methadone and morphine in regulation of delta-opioid receptors underlies the antagonistic effect of methadone on morphinemediated cellular actions. Eur J Pharmacol 373: 233-239.

Lyvers M, Yakimoff M (2003). Neuropsychological correlates of opioid dependence and withdrawal. Addictive Behav 28: 605-611.

Madden GJ, Bickel WK, Jacobs EA (1999). Discounting of delayed rewards in opioid-dependent outpatients: exponential or hyperbolic discounting functions? Exp Clin Psychopharmacol 7: 284-293.

Maldonador RAFA (1997). Participation of noradrenergic pathways in the expression of opiate withdrawal: biochemical and pharmacological evidence. Neurosci Biobehav Rev 21: 91-104.

Mintzer MZ, Copersino ML, Stitzer ML (2005). Opioid abuse and cognitive performance. Drug Alcohol Dependence 78: 225-230.

Mintzer MZ, Stitzer ML (2002). Cognitive impairment in methadone maintenance patients. Drug Alcohol Dependence 67: 41-51.

Murphy FC, Michael A, Robbins TW, Sahakian BJ (2003). Neuropsychological impairment in patients with major depressive disorder: the effects of feedback on task performance. Psychol Med 33: 455-467.

Neiman J, Haapaniemi HM, Hillbom M (2000). Neurological complications of drug abuse: pathophysiological mechanisms. Eur J Neurol 7: 595-606.

Nelson HE (1982). National Adult Reading Test Manual. NFERNelson: Windsor (UK).

Nestler EJ, Alreja M, Aghajanian GK (1999). Molecular control of locus coeruleus neurotransmission. Biol Psychiatr 46: 1131-1139.

Petry NM (2003). Discounting of money, health, and freedom in substance abusers and controls. Drug Alcohol Dependence 71: 133-141.

Rainville P (2002). Brain mechanisms of pain affect and pain modulation. Curr Opin Neurobiol 12: 195-204.

Robinson TE, Berridge KC (1993). The neural basis of drug craving - an incentive-sensitization theory of addiction. Brain Res Rev 18: 247-291.

Rogers RD, Lancaster M, Wakeley J, Bhagwagar Z (2004). Effects of beta-adrenoceptor blockade on components of human decisionmaking. Psychopharmacology 172: 157-164.

Rogers RD, Owen AM, Middleton HC, Williams EJ, Pickard JD, Sahakian BJ et al (1999). Choosing between small, likely rewards and large, unlikely rewards activates inferior and orbital prefrontal cortex. J Neurosci 19: 9029-9038.

Rogers RD, Tunbridge EM, Bhagwagar Z, Drevets WC, Sahakian BJ, Carter CS (2003). Tryptophan depletion alters the decisionmaking of healthy volunteers through altered processing of reward cues. Neuropsychopharmacology 28: 153-162. 
Selye H (1952). The Story of the Adaptation Syndrome. Acta Inc. Montreal, Quebec, Canada.

Spotts JV, Shonts FC (1980). A life-theme theory of chronic drug abuse. In: Lettieri DJ, Sayers M, Wallenstein-Pearson H (eds). Theories on Drug Abuse-Selected Contemporary Perspectives. National Institute on Drug Abuse: Rockville, Maryland. pp 59-70.

Stine SM, Grillon CG, Morgan CA, Kosten TR, Charney DS, Krystal JH (2001). Methadone patients exhibit increased startle and cortisol response after intravenous yohimbine. Psychopharmacology 154: 274-281.

Stine SM, Southwick SM, Petrakis IL, Kosten TR, Charney DS, Krystal JH (2002). Yohimbine-induced withdrawal and anxiety symptoms in opioid- dependent patients. Biol Psychiatr 51: 642-651.
UK Department of Health (1999). Drug Misuse and Dependence Guidelines on Clinical Management. The Stationery Office Ltd.: Norwich.

Wise RA (1988). The neurobiology of craving - implications for the understanding and treatment of addiction. J Abnormal Psychol 97: 118-132.

Wolff K (2003). Plasma methadone monitoring: an aid to dose assessment, monitoring compliance and exploration of drug interactions. In: Tober G, Strang J (eds). Methadone Matters: Evolving Community Methadone Treatment of Opiate Addiction. Martin Dunitz/Taylor\&Francis Group: London. pp 67-77.

Yucel M, Wood SJ, Fornito A, Riffkin J, Velakoulis D, Pantelis C (2003). Anterior cingulate dysfunction: implications for psychiatric disorders? J Psychiatr Neurosci 28: 350-354. 